\title{
Manajemen Pemeliharaan untuk Menurunkan Tingkat Mortalitas Pedet Sapi Bali
}

\section{(Maintenance Management to Decrease Mortality Rate of Bali Calves)}

\author{
Achadri Y, Sendow CJB, Ratnawaty S \\ Balai Pengkajian Teknologi Pertanian NTT, PO Box 1022, Naibonat Kupang 85362 \\ yanuarachadri@pertanian.go.id,yanachadri1988@gmail.com
}

\begin{abstract}
The research was carried out to decrease the mortality rate of Bali calves. This research was conducted at the Trial Farm of BPTP NTT for 3 years, it started in 2016 until 2018. The material used in this research was Bali calves, communal shed, and separate shed. The data collection system is carried out by observing the population of Bali calves every year. In 2016-2017, Bali calves were maintenanced in communal shed; in 2018-2019 in a separate shed. The results of Bali calves mortality research were highest in 2017, that was with the calves maintenance system combined in communal shed with adult cattle. After the treatment of Bali calves separation from broodstock in 2018, the percentage of mortality rate decreased. The high mortality rate of calves is one of them caused by competition in feed between adult cows and Bali calves which causes nutrition obtained by calves for a period of growth and development was not optimal. The steps to reduce the mortality rate i.e separation of Bali calves from adult cows in a special of Bali calves separation shed.
\end{abstract}

Key words: Maintenance management, mortality, Bali calves

\begin{abstract}
ABSTRAK
Penelitian ini bertujuan untuk menurunkan tingkat mortalitas pedet sapi Bali. Penelitian ini dilaksanakan di Kandang Percobaan BPTP NTT selama 3 tahun, dimulai tahun 2016 sampai 2018. Materi yang digunakan dalam penelitian ini adalah pedet ternak sapi Bali, kandang komunal, dan kandang pisah. Sistem pengambilan data dilakukan tiap tahun dengan mengamati populasi pedet sapi Bali. Pada tahun 2016-2017, pedet sapi Bali dipelihara di kandang komunal, sedangkan tahun 2018 dipelihara di kandang pisah. Hasil perlakuan pemisahan pedet dari indukan pada tahun 2016 persentase mortalitas 55,56\%, tahun 2017 mortalitas 72,73\%, dan tahun 2018 mortalitas $15,38 \%$. Hasil penelitian mortalitas pedet sapi Bali tertinggi terjadi pada tahun 2017, yaitu dengan sistem pemeliharaan pedet digabung di kandang komunal dengan ternak sapi dewasa. Setelah ada perlakuan pemisahan pedet dari indukan pada tahun 2018, persentase mortalitas menurun. Angka mortalitas pedet yang tinggi ini salah satunya disebabkan karena ada kompetisi dalam pakan antara sapi dewasa dengan sapi pedet sehingga menyebabkan nutrisi yang diperoleh pedet untuk masa pertumbuhan dan perkembangan kurang optimal. Upaya yang dilakukan untuk menekan tingkat mortalitas yakni memisahkan sapi-sapi pedet dari sapi-sapi dewasa di kandang pisah khusus pedet.
\end{abstract}

Kata kunci: Manajemen pemeliharaan, mortalitas, pedet sapi Bali 


\section{PENDAHULUAN}

Sapi Bali banyak dikembangkan di lahan suboptimal berupa lahan kering dengan curah hujan rendah. Pada beberapa tempat di Indonesia, lahan didominasi lahan kering beriklim kering, kondisi seperti ini terlihat di provinsi Nusa Tenggara Timur (BPS Provinsi Nusa Tenggara Timur 2017). Sapi Bali merupakan salah satu komoditas unggulan sumber pendapatan petani peternak untuk meningkatkan perekonomian di Provinsi NTT. Provinsi Nusa Tenggara Timur (NTT) merupakan salah satu wilayah yang sebagian besar lahannya berupa lahan kering dan musim hujan atau bulan basah pendek yaitu sekitar 3-4 bulan, sedangkan bulan kemarau/kering berlangsung panjang, yaitu antara 8-9 bulan (BPS Provinsi Nusa Tenggara Timur 2017). Namun, NTT dikenal sebagai salah satu sentra ternak sapi potong di Indonesia yang didukung dengan areal lahan luas, namun lahan penggembalaan banyak yang belum termanfaatkan. Luas area padang penggembalaan di NTT mencapai 832.228 ha berpotensi untuk mendukung pengembangan sapi dengan pola pemeliharaan ekstensif (Priyanto 2016). Pada tahun 2016, populasi sapi di NTT menempati urutan kelima dari populasi sapi potong nasional dengan populasi sebanyak 984.508 ekor (BPS 2017; Ditjen PKH 2017). Hal ini menjadikan perhatian pemerintah daerah untuk tetap mempertahankan tingginya populasi sapi potong di kawasan NTT.

Sapi Bali merupakan bangsa sapi yang dominan di wilayah NTT dan hingga kini telah berkembang cukup pesat. Hal ini karena sapi Bali mampu beradaptasi pada kondisi iklim kering dengan persediaan pakan hijauan yang relatif rendah, namun masih mampu untuk bereproduksi. Jumlah kepemilikan sapi Bali di NTT bervariasi tergantung pada daya dukung fisik wilayah, iklim, tingkat produktivitas ternak, kemampuan tenaga kerja petani dan faktor keamanan (pencurian ternak) (Mullik \& Jelantik 2009).

Upaya peningkatan produktivitas Sapi Bali dilakukan dengan cara memperbaiki manajemen pemeliharaan salah satunya di lingkungan kandang yang sangat berpengaruh terhadap kesejahteraan hidup ternak. Pedet di dalam kandang komunal seringkali mengalami masalah dalam kompetisi pakan, sehingga pemeliharaan pedet sejak lahir sampai disapih menjadi sangat penting dalam upaya menyediakan bakalan baik sebagai pengganti induk maupun untuk digemukan sebagai ternak pedaging. Pedet adalah anak sapi yang baru lahir hingga umur 8 bulan. Pedet yang baru lahir membutuhkan perawatan khusus, ketelitian, kecermatan dan ketekunan dibandingkan dengan pemeliharaan sapi dewasa. Pemeliharaan pedet mulai dari lahir hingga disapih merupakan bagian penting dalam kelangsungan pemeliharaan manajemen ternak sapi (Purwanto \& Muslih 2006).

Pemeliharaan sapi Bali khususnya pedet yang dipelihara di kandang BPTP Balitbangtan NTT yakni, dilakukannya pemisahan kandang pedet di dalam kandang komunal dengan teknik membuat kandang yang hanya bisa dimasuki oleh pedet sehingga pedet dapat keluar masuk leluasa untuk makan dan minum, serta menyusu ke induknya. Penerapan manajemen pemeliharaan ini perlu dilakukan sejak pedet baru lahir untuk mencegah kematian pedet yang tinggi. Menurut Purwanto \& Muslih (2006), sekitar 25$30 \%$ dari pedet yang lahir akan mengalami mortalitas pada periode umur 4 bulan pertama. Kondisi pemeliharaan di kandang BPTP Balitbangtan NTT, mortalitas pedet umumnya disebabkan oleh pedet berkompetisi dalam hal mendapatkan pakan dengan sapi dewasa di kandang komunal yang menyebabkan pedet kekurangan jumlah konsumsi pakan maupun asupan nutrisi dari pakan.

Tujuan dari penelitian ini adalah untuk menurunkan tingkat mortalitas pedet sapi Bali di kandang BPTP NTT. Teknik yang dilakukan untuk menurunkan mortalitas pedet sapi Bali adalah pada manajemen pemeliharaannya, dengan cara melakukan pemisahan 
kandang pedet di dalam kandang komunal diharapkan dapat menekan angka kematian pedet.

\section{MATERI DAN METODE}

\section{Lokasi dan waktu penelitian}

Penelitian ini dilaksanakan di Kandang Percobaan BPTP Balitbangtan Nusa Tenggara Timur, selama 3 tahun, dimulai tahun 2016 sampai Juni 2019.

\section{Materi penelitian}

Materi yang digunakan dalam penelitian ini adalah pedet ternak sapi Bali, mulai dari tahun 2016 berjumlah 9 ekor, tahun 2017 berjumlah 8 ekor, tahun 2018 berjumlah 4 ekor, dan tahun 2019 berjumlah 8 ekor, kandang komunal sapi Bali dengan ukuran 30 meter x 30 meter, kandang pisah khusus pedet sapi Bali dengan ukuran 2,5 meter x 6 meter, ear tag, dan seperangkat alat tulis menulis.

\section{Metode penelitian}

Sistem pengambilan data dilakukan dengan mengamati jumlah populasi perkembangan dan pertumbuhan pedet sapi Bali tiap tahun. Pada tahun 2016 sampai 2017, pedet sapi Bali dipelihara di kandang komunal; tahun 2018, pedet sapi Bali dipelihara di kandang pisah (khusus pedet sapi Bali umur 1 bulan sampai 4 bulan). Perlakuan pedet sapi Bali yang dipelihara di kandang komunal dan kandang pisah tersebut dilakukan pengamatan tiap tahun mengenai data kematian atau mortalitas. Apabila ada pedet yang mati maka dilakukan pencatatan dan penghitungan dengan rumus sebagai berikut:

Persentase kematian $(\%)=\sum \sum$ kematian pedet sapi $/$ tahun $\times 100 \%$

$\sum$ populasi pedet sapi / tahun

Setelah data mortalitas diketahui maka dilakukan analisis secara deskriptif mengenai hasil pengamatan mortalitas tiap tahun pemeliharaan pedet sapi Bali di kandang BPTP NTT.

\section{HASIL DAN PEMBAHASAN}

\section{Data populasi ternak sapi Bali di kandang BPTP Balitbangtan NTT}

Kandang BPTP Balitbangtan NTT memelihara ternak sapi Bali dengan jumlah populasi yang dipelihara disajikan pada tabel 1 sebagai berikut. 
Tabel 1. Data Populasi Sapi Bali di Kandang BPTP Balitbangtan NTT Tahun 2016-2018

\begin{tabular}{|c|c|c|c|c|c|c|c|c|c|c|c|c|}
\hline \multirow{2}{*}{ Ternak sapi } & \multicolumn{4}{|c|}{ Tahun 2016} & \multicolumn{4}{|c|}{ Tahun 2017} & \multicolumn{4}{|c|}{ Tahun 2018} \\
\hline & Paw & $\mathrm{L}$ & $\mathrm{M}$ & PAk & Paw & $\mathrm{L}$ & $\mathrm{M}$ & PAk & PAw & $\mathrm{L}$ & M & PAk \\
\hline Jantan dewasa & 3 & & & 3 & 4 & & & 4 & 4 & & & 4 \\
\hline Betina dewasa & 16 & & & 16 & 16 & & & 16 & 18 & & & 18 \\
\hline Jantan muda & 1 & & & 1 & 0 & & & 0 & 1 & & & 1 \\
\hline Betina dara & 6 & & & 6 & 6 & & 4 & 2 & 2 & & & 2 \\
\hline Pedet jantan & 0 & 3 & 2 & 1 & 1 & 2 & 2 & 1 & 1 & 2 & 1 & 2 \\
\hline Pedet betina & 0 & 6 & 3 & 3 & 3 & 5 & 6 & 2 & 2 & 8 & 1 & 9 \\
\hline Total & 26 & 9 & 5 & 30 & 30 & 7 & 12 & 25 & 28 & 10 & 2 & 36 \\
\hline
\end{tabular}

PAw: Populasi awal, L: Lahir, M: Mati, Pak: Populasi akhir

Ternak sapi Bali yang dipelihara di kandang BPTP NTT terdiri dari: jantan dewasa, betina dewasa, jantan muda, betina dara, pedet jantan, dan pedet betina. Ternak sapi Bali pejantan dan betina dewasa adalah ternak sapi yang sudah siap kawin, untuk pejantan disiapkan untuk mengawini betina sedangkan untuk betina disiapkan sebagai induk penghasil pedet. Ternak sapi Bali pejantan muda dan betina dara disiapkan sebagai calon pejantan dan calon indukan. Ternak sapi Bali pedet ini disiapkan sebagai calon bibit unggul sapi Bali. Data populasi ternak sapi Bali di kandang BPTP NTT diamati mulai tahun 2016 dengan jumlah total sebanyak 30 ekor, tahun 2017 sejumlah 25 ekor, dan tahun 2018 sebanyak 36 ekor. Hasil pengamatan data populasi ternak sapi Bali yang diamati mulai tahun 2016 sampai 2018 ini yang paling menurun tajam terlihat pada tahun 2017 dengan populasi akhir sejumlah 25 ekor. Hal ini disebabkan tingginya kematian pedet pada tahun 2017, sehingga perlu dilakukan perhatian pemeliharaan khusus pada pedet sapi Bali.

Pemeliharaan pedet memerlukan perhatian dan ketelitian yang tinggi dibanding dengan pemeliharaan sapi dewasa. Hal ini disebabkan karena kondisi pedet yang masih lemah sehingga bisa menimbulkan angka kematian yang tinggi. Kesalahan dalam pemeliharaan pedet bisa menyebabkan pertumbuhan pedet terhambat dan tidak maksimal. Penanganan pedet sapi Bali dengan baik diperlukan, agar nantinya diperoleh sapi Bali yang mempunyai produktivitas tinggi untuk menggantikan sapi yang tidak berproduksi lagi.

\section{Kondisi perkandangan dan lingkungan}

Kondisi perkandangan di BPTP Balitbangtan NTT berbentuk kandang komunal beratap sebagian. Kadang koloni/ kelompok atau kandang komunal adalah model kandang dalam suatu ruangan yang menempatkan beberapa ekor ternak secara bebas tanpa diikat. Bentuk kandang komunal yang ada di BPTP Balitbangtan NTT disajikan pada gambar 1 sebagai berikut. 
Achadri et al.: Manajemen Pemeliharaan untuk Menurunkan Tingkat Mortalitas Pedet Sapi Bali

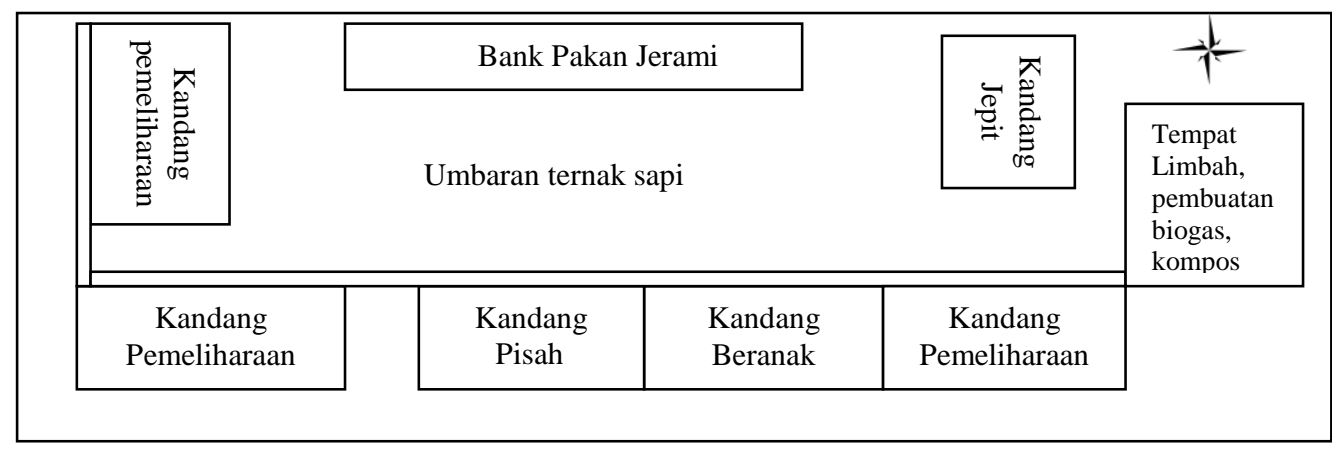

Gambar 1. Denah perkandangan sapi Bali di BPTP Balitbangtan NTT

Perkandangan di BPTP NTT mempunyai luas 30 meter x 30 meter. Kandang kelompok beratap sebagian merupakan kandang kelompok yang pada bagian depan kandang (terutama tempat palungan) ditutupi oleh atap. Kandang kelompok model ini identik dengan kandang umbaran terbatas. Kandang model umbaran adalah kandang yang dibuat dengan ukuran lebih besar dengan tujuan agar ternak dapat melakukan aktivitas lebih leluasa. Bagian belakang kandang dilengkapi selokan pembuangan, terutama untuk menjaga kebersihan lantai kandang pada musim hujan. Pembuangan feses dilakukan secara berkala, yaitu 3-4 kali setahun atau sesuai kebutuhan. Kelebihan sistem perkandang ini adalah ternak lebih bebas dan adanya rak penyimpanan pakan kering seperti jerami (bank pakan) sehingga pakan hijauan kering selalu tersedia.

\section{Manajemen pemeliharaan}

Pemeliharaan ternak sapi Bali di kandang BPTP Balitbangtan NTT menggunakan model semi intensif, yaitu ternak sapi dikandangkan pada malam hari dan digembalakan pada pagi sampai sore hari tergantung kondisi lingkungan dan iklim cuaca. Ternak sapi di BPTP NTT digembalakan di lahan tanaman pangan yang sudah dipanen selama pergantian musim tanam karena pada saat pergantian musim tanam hasil limbah pertanian bisa dimanfaatkan sebagai pakan ternak. Luas lahan tanaman pangan di BPTP NTT seluas 18 Ha. Pada masa pergantian musim, lahan tanaman pangan yang sudah panen ini digunakan untuk penggembalaan ternak. Kelebihan ternak digembalakan yaitu ternak dapat memilih sendiri pakan yang ada di lahan penggembalaan.

Ketersediaan pakan dan teknik pemberian pakan di kandang BPTP NTT yaitu ternak disediakan bank pakan yang terbuat dari bambu diletakkan di tengah kandang komunal, diisi dengan pakan basal yaitu jerami kering, kemudian diberikan pakan tambahan berupa pakan lokal: dedak, putak, hijauan-hijauan segar antara lain; hijauan lamtoro taramba, legume, gamal, rumput raja, dan batang jagung. Pemberian air minum diberikan selalu tersedia di tempat minum (ad libitum).

Pemberian pakan ke ternak sapi Bali dewasa diberikan di tempat wadah pakan sesuai kebutuhan dan disediakan bank pakan berisi jerami, sehingga ternak tidak pernah kehabisan pakan. Pemberian ke ternak pedet lebih diperhatikan lagi, yaitu dengan cara pakan disediakan di tempat pakan khusus kandang pedet, sehingga pedet dapat terpenuhi nutrisi tubuhnya tanpa kekurangan dan berebutan makanan dengan sapi-sapi dewasa.

Menurut Hadi et al. (2002) mengatakan bahwa pengembangan sapi Bali di NTT didukung oleh potensi sumber daya lokal dan lahan yang luas. Namun demikian, pemeliharaan sapi di NTT ini sebagian besar masih menggunakan sistem usaha tradisional dengan produktivitas relatif rendah. Sapi Bali sebagian besar dipelihara secara 
ekstensif dengan cara digembalakan pada padang penggembalaan alam. Padang penggembalaan ini, jika dilakukan perbaikan dengan introduksi rumput dan leguminosa unggul, akan meningkatkan kapasitas tampungnya. Namun, jika padang penggembalaan tersebut tidak dikelola dengan baik, akan berdampak pada menurunnya ketersediaan pakan terutama musim kemarau. Hal ini dapat berdampak pada relatif rendahnya produktivitas akibat penurunan angka kelahiran, tingkat mortalitas pedet yang tinggi.

Salah satu cara untuk menekan mortalitas pedet menurut Ellyza (2011), dengan memperhatikan langkah awal yang harus dilakukan terhadap pedet yang baru lahir adalah membersihkan lendir di dalam rongga mulut dan rongga hidung serta mengeringkan bulunya yang dapat dilakukan dengan baik oleh induknya sendiri. Tali pusar dipotong pendek ( $\pm 2 \mathrm{~cm}$ dari pangkalnya) dan diberi yodium segera mungkin setelah kelahiran untuk mencegah infeksi. Biarkan pedet bersama induk selama 40-72 jam, agar pedet mendapat kolostrum dan menggertak induk untuk mengeluarkan susu dengan mudah dan lancar. Pedet yang baru lahir ditempatkan dalam kandang khusus pedet serta dijaga supaya pedet dan alas kandangnya tetap kering. Pemeliharaan pedet yang terpenting adalah pedet harus mendapatkan kolostrum (yaitu susu yang dihasilkan oleh induk yang baru melahirkan) yang dihasilkan induk hingga 1 minggu setelah kelahiran sebanyak tidak lebih dari $6 \%$ berat badannya.

\section{Pengaruh kandang pisah terhadap mortalitas pedet}

Sapi Bali indukan yang telah melahirkan anakan pedet, setelah 2 minggu pedet mulai dipisahkan dari induknya secara bertahap dan pedet mulai dikenalkan pakan hijauan sedikit demi sedikit. Hal ini berfungsi untuk menyapih pedet dan mulai memisahkan pedet dari induknya ke kandang pisah khusus pedet. Model kandang pisah khusus pedet ini sederhana, berbentuk sekat, pintu terbuat dari bambu yang diberi lubang sesuai ukuran tubuh pedet, sehingga hanya pedet yang dapat keluar masuk dengan leluasa. Fungsi utama kandang pisah ini antara lain: pedet tidak terganggu oleh ternak sapi dewasa dalam memperoleh pakan, pedet dapat keluar masuk dengan leluasa apabila ingin enyusu ke induknya, dan pedet dapat hidup nyaman tanpa gangguan ternak sapi dewasa. Model kandang pisah dapat dilihat pada gambar 2.

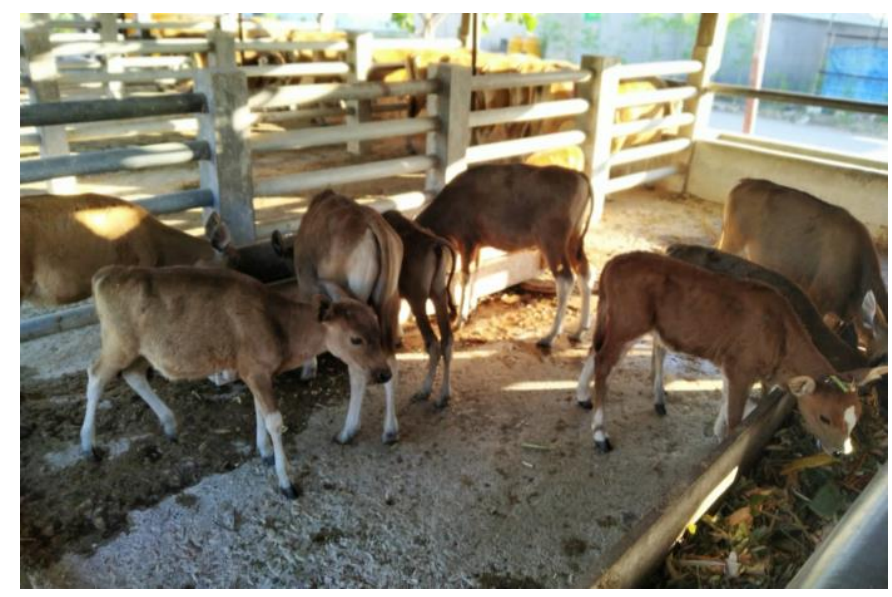

Gambar 2. Kandang pisah pedet sapi Bali umur 2 minggu -4 bulan di kandang BPTP NTT 
Pada tahun 2016 sampai 2018 di kandang percobaan BPTP NTT mulai dilakukan pengamatan pemeliharaan ternak sapi, khususnya pedet. Tahun 2016-2017, pedet dipelihara secara gabung dengan ternak sapi dewasa di kandang komunal, sedangkan tahun 2018 sampai sekarang ini pedet dipelihara secara terpisah dari ternak sapi dewasa di kandang pisah khusus pedet. Hasil penelitian dan pengamatan selama 3 (tiga) tahun adalah sebagai berikut (Gambar 3).

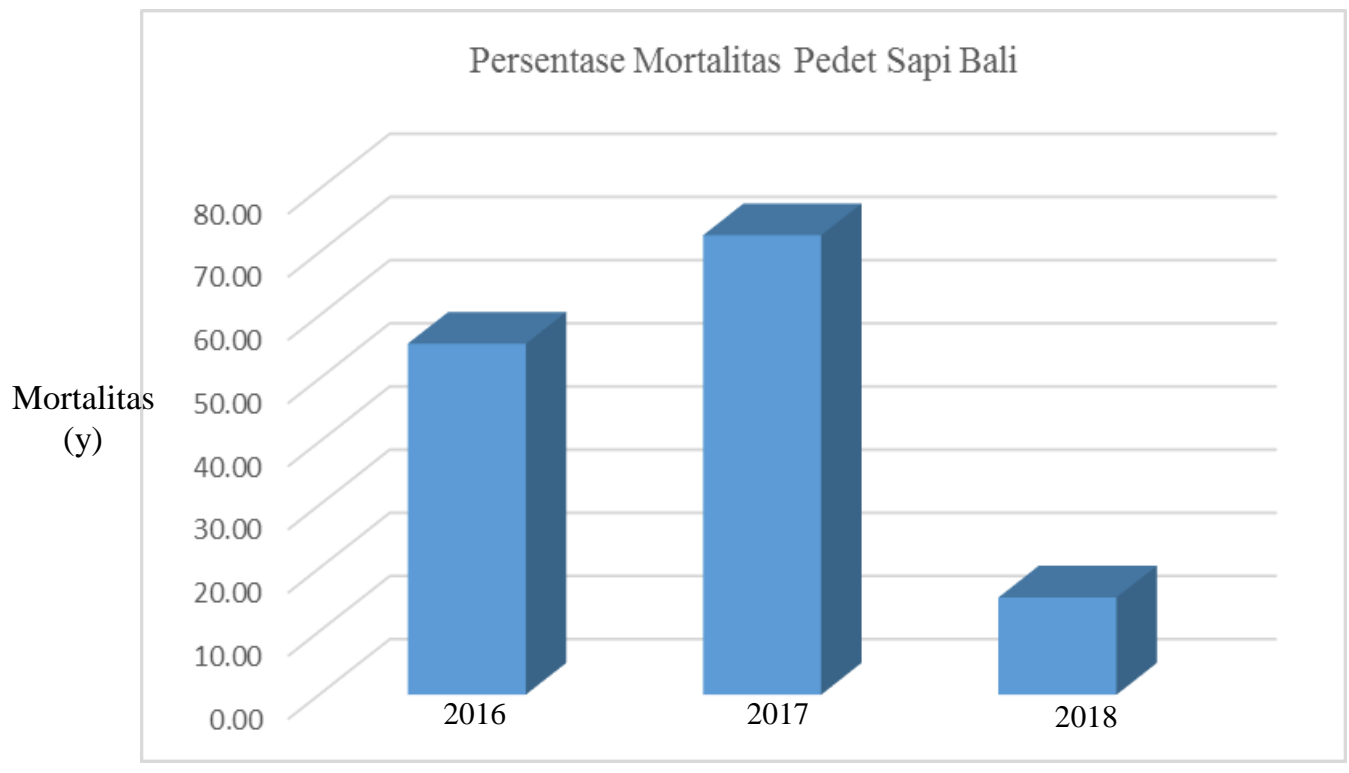

Tahun (x)

Gambar 3. Grafik persentase mortalitas pedet sapi Bali di kandang BPTP NTT tahun 20162018

Hasil perlakuan pemisahan pedet dari indukan apabila diamati dari grafik persentase mortalitas pedet sapi Bali di kandang percobaan BPTP NTT tersebut yaitu pada tahun 2016 persentase mortalitas 55,56\%, tahun 2017 persentase mortalitas tertinggi mencapai $72,73 \%$, dan tahun 2018 persentase mortalitas menurun 15,38\%. Hasil pengamatan dan penelitian mortalitas pedet sapi Bali tertinggi terjadi pada tahun 2017, yaitu dengan sistem pemeliharaan pedet digabung di kandang komunal dengan ternak sapi-sapi dewasa. Setelah ada perlakuan pemisahan pedet dari indukan pada tahun 2018, persentase mortalitas menurun.

Angka mortalitas pedet yang tinggi ini salah satunya disebabkan karena ada kompetisi dalam memperoleh pakan antara sapi-sapi dewasa dengan sapi-sapi pedet yang dipelihara di dalam kandang komunal. Pada saat sapi dewasa berebut pakan dengan sapi pedet biasanya berdesak-desakan, maka timbul luka pada pedet dan feed intake yang masuk dalam tubuh pedet sedikit, sehingga menyebabkan nutrisi yang diperoleh pedet untuk masa pertumbuhan dan perkembangan kurang optimal. Menurut Johnsen et al. (2018), upaya tindakan yang dilakukan untuk menekan tingkat mortalitas yang tinggi salah satunya memisahkan sapi-sapi pedet dari sapi-sapi dewasa di kandang pisah khusus pedet.

Menurut Rahayu (2014) berdasarkan hasil penelitian, angka mortalitas pedet pada peternakan rakyat torgolong tinggi, yaitu sebesar 48 ekor dari 245 ekor pedet sampel penelitian (19, 59\%). Angka kematian yang tinggi ini menunjukkan manajemen 
pemeliharaan pedet yang tergolong buruk. Manajemen pemeliharaan pedet tergolong baik, jika mortalitas 1\%, sedangkan apabila mortalitas mencapai angka sebesar 20\%$25 \%$, menunjukkan manajemen pemeliharaan yang buruk. Selain itu, tingkat mortalitas pedet dipengaruhi oleh musim, hal ini sesuai dengan pernyataan Uza \& Adee (2005) bahwa tingkat kematian pedet saat musim dingin lebih tinggi daripada saat musim panas. Kematian pedet pada musim panas disebabkan oleh kekurangan nutrisi, akibat penurunan konsumsi pakan.

Kondisi pemeliharaan pedet di kandang BPTP NTT sampai bulan Juni 2019 ini masih dilakukannya pemisahan kandang pedet di dalam kandang komunal dengan teknik membuat kandang pisah yang hanya bisa dimasuki oleh pedet. Jumlah pedet bulan Juni 2019 bertambah 1 ekor dan beberapa sapi indukan bunting, prediksi bulan Juli-September ada kelahiran pedet. Data sampai Juni 2019 ini belum ada mortalitas pedet sapi Bali.

\section{KESIMPULAN}

Manajemen pemisahan kandang pedet dalam kandang komunal dengan memperhatikan kecukupan pakan dan nutrisi dapat menekan angka mortalitas pedet.

\section{DAFTAR PUSTAKA}

[BPS] Badan Pusat Statistik. 2017. Statistik Indonesia 2016. Jakarta (Indonesia): Badan Pusat Statistik.

[BPS NTT] Badan Pusat Statistik Provinsi Nusa Tenggara Timur. 2017. Nusa Tenggara Timur dalam angka 2016. Kupang (Indonesia): Badan Pusat Statistik Povinsi Nusa Tenggara Timur.

Ditjen PKH. 2017. Statistik peternakan 2016. Jakarta (Indonesia): Direktorat Jenderal Peternakan dan Kesehatan Hewan, Kementerian Pertanian.

Ellyza N. 2011. Manajemen sapi perah. Yogyakarta (Indonesia): Graha Ilmu.

Hadi PU, Ilham N, Thahar A, Winarso B, Vincent D, Quirke D. 2002. Improving Indonesia's beef industry. Canberra (Australia): ACIAR.

Johnsen J, Mejdell CM, Beaver A, Passille AM, Rushen J, Weary D. 2018. Behavioural Responses to Cow-Calf Separation: The Effect of Nutritional Dependence. Appl Anim Behav Sci. 201:1-6.

Mullik M, Jelantik IGN. 2009. Strategi peningkatan produktivitas sapi Bali pada sistem pemeliharaan ekstensif di daerah lahan kering: Pengalaman Nusa Tenggara Timur. Dalam: Prosiding Seminar Nasional Pengembangan Sapi Bali Berkelanjutan dalam Sistem Peternakan Rakyat. Mataram (Indonesia): BPTP NTB bekerjasama dengan Universitas Mataram dan Dinas Peternakan Provinsi NTB.

Priyanto D. 2016. Strategi pengembalian wilayah Nusa Tenggara Timur sebagai sumber ternak sapi potong. J Penelitian Pengembangan Pertanian. 35:167-178.

Purwanto H, Muslih D. 2006. Tatalaksana pemeliharaan pedet sapi perah. Prosiding Temu Teknis Nasional Tenaga Fungsional Pertanian 2006. Bogor (Indonesia): Kementerian Pertanian.

Rahayu ID. 2014. Identifikasi penyakit pada pedet perah pra-sapih di peternakan rakyat dan perusahaan peternakan. J Gamma. 9:40-49.

Uza DV, Adee AA. 2005. Causes and costs of caf mortality at government research and private. Farm in The Dry Subhamid Savanna Zoe of Nigeria. Niger Vet J. 26. 